Research Paper

\title{
Circulating EBV DNA, Globulin and Nodal Size Predict Distant Metastasis after Intensity-Modulated Radiotherapy in Stage II Nasopharyngeal Carcinoma
}

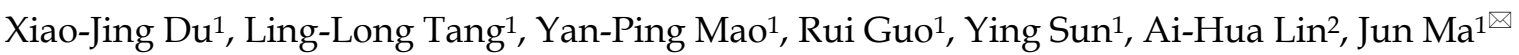 \\ 1. Sun Yat-sen University Cancer Center; State Key Laboratory of Oncology in South China; Collaborative Innovation Center for Cancer Medicine, Department \\ of Radiation Oncology, Guangzhou 510060, China; \\ 2. Department of Medical Statistics and Epidemiology, School of Public Health, Sun Yat-sen University, No. 74 Zhongshan Road, Guangzhou 510060, China. \\ $\square$ Corresponding author: Jun Ma, M.D., Sun Yat-sen University Cancer Center; State Key Laboratory of Oncology in South China; Collaborative Innovation \\ Center for Cancer Medicine, Department of Radiation Oncology, Guangzhou 510060, People's Republic of China. Telephone: +86-20-87343469 Fax: \\ +86-20-87343295 E-mail: majun2@mail.sysu.edu.cn.
}

(0) Ivyspring International Publisher. Reproduction is permitted for personal, noncommercial use, provided that the article is in whole, unmodified, and properly cited. See http://ivyspring.com/terms for terms and conditions.

Received: 2015.10.20; Accepted: 2016.01.22; Published: 2016.03.20

\begin{abstract}
Background: The optimal treatment for early-stage nasopharyngeal carcinoma (NPC) remains controversial. Identification of prognostic factors for metastasis and tumor progression is urgently required to improve clinical decision-making for patients with American Joint Committee on Cancer (AJCC) 2009 stage II NPC from the endemic area.

Methods: Consecutive newly-diagnosed patients $(n=296)$ with non-disseminated, biopsy-proven stage II NPC were retrospectively reviewed; all patients received intensity-modulated radiotherapy and MRI follow-up. Plasma EBV DNA level, serum lactate dehydrogenase, serum albumin, serum globulin and leukocyte counts were measured before therapy. Survival rates were analyzed using the Kaplan-Meier method and log-rank test and multivariate Cox proportional hazards model.

Results: Median follow-up was 50.2 months (range, 8-69.5 months). Multivariate analysis demonstrated a plasma Epstein-Barr virus (EBV) DNA level $\geq 4000$ copies $/ \mathrm{mL}$, maximal axial diameter (MAD) of the cervical lymph nodes $\geq 30 \mathrm{~mm}$ and serum globulin level $<29.5 \mathrm{~g} / \mathrm{L}$ were independent predictors of poor DMFS $(P=0.018 ; P=0.019 ; P=0.006$, respectively). On the basis of these parameters, a prognostic model was developed as follows: 1) patients with no risk factors; 2) one risk factor; and 3) two or three risk factors. The 3-year distant metastasis-free survival rates for groups 1,2 and 3 were $100 \%, 94.6 \%$ and $84.3 \%$, respectively $(P=0.001)$.

Conclusion: The prognostic model based on EBV DNA, serum globulin and nodal size may facilitate individualized treatment of patients with stage II NPC at high risk of distant metastasis.
\end{abstract}

Key words: prognostic model, Epstein-Barr virus DNA, serum globulin, nodal size, metastasis, nasopharyngeal carcinoma.

\section{Introduction}

Nasopharyngeal carcinoma (NPC) is endemic in Southeast Asia, with an annual incidence of $30-80$ per 10,000 [1]. NPC is usually poorly differentiated or undifferentiated, in a complex anatomic location and has a high radiosensitivity. The current standard therapy is combined chemotherapy and radiotherapy for locally advanced NPC and radiotherapy alone for early-stage disease [2]. Patients with American Joint Committee on Cancer (AJCC) 2009 stage II NPC appear to have a relatively favorable prognosis and are generally excluded from trials of combined modality treatments [3]. However, a significant heterogeneity in treatment outcomes is observed for patients within the same clinical stages and a subset of 
patients with stage II NPC are considered to be at higher risk of tumor progression [4].

In several retrospective studies of early-stage NPC patients, distant metastasis was the predominant pattern of failure after radiotherapy alone [5-8]. Chen et al. published the first randomized phase III prospective study and demonstrated concurrent chemoradiotherapy was associated with better distant control and overall survival in patients with stage II NPC undergoing two-dimensional conventional radiotherapy (2D-CRT) [9]. In recent years, intensity-modulated radiation therapy (IMRT) has gradually replaced 2D-CRT as the primary radiotherapy modality in NPC as a result of its improved dose distribution and ability to increase locoregional control and long-term survival $[10,11]$. However, distant control remains unsatisfactory [2, 6-8]. Due to the uncertainty regarding the value of chemotherapy in stage II NPC in the IMRT era, it would be of clinical interest to identify prognostic factors for distant metastasis or tumor progression that would enable physicians to identify subgroups of patients who may benefit from more aggressive individualized therapy.

Although the Tumor, Node, Metastasis (TNM) staging system is generally accepted as the most valuable prognostic factor to guide therapy in NPC, accumulating data suggests that the plasma Epstein-Barr virus (EBV) DNA level and several other serum markers may be useful prognostic factors for distant metastasis after treatment in NPC [4,12-15]. Therefore, the aims of the present study were to evaluate the prognostic value of a number of clinical characteristics and laboratory variables and design a prognostic model for distant metastasis in patients with AJCC 2009 stage II NPC.

\section{Patients and methods}

\section{Patients}

All patients with newly diagnosed, biopsy-proven, non-metastatic NPC treated at Sun Yat-sen University Cancer Center using IMRT between October 2009 and February 2012 were retrospectively analyzed. In all, 1811 patients were evaluated, of whom 381 (21.0\%) were diagnosed with stage II disease according to the 7 th edition of the AJCC staging system [16]. Of these, 85/381 (22.3\%) cases were subsequently eliminated as a result of lacking complete laboratory data. Thus, 296 patients were included in this analysis. The study was performed after the ethical approval from Institutional Review Board of Sun Yat-sen University Cancer Center. Informed consent was obtained from each patient for their consent to have their information used in research without affecting their treatment option or violating their privacy.

\section{Image assessment}

All patients underwent MRI using a 1.5-T system to examine the region from the suprasellar cistern to the inferior margin at the sternal end of the clavicle with a head-and-neck combined coil. Two experienced radiologists separately evaluated the MRI images; disagreements were resolved by consensus. The diagnostic criteria for metastatic lymphadenopathy were in accordance with van den Brekel et al. and Tang et al. [17, 18]. Extracapsular spread of cervical lymph nodes was defined as the presence of indistinct nodal margins, irregular nodal capsular enhancement or infiltration into adjacent fat or muscle [17]. The location(s) of positive lymph nodes and the maximal axial diameter (MAD) in the largest plane based on cross-sectional imaging for the cervical lymph nodes were recorded.

\section{Laboratory measurements}

Plasma EBV DNA level, serum lactate dehydrogenase, serum albumin, serum globulin and leukocyte counts were measured at the same time within 2 weeks before initiation of therapy in all patients. Plasma EBV DNA level was measured using a real-time quantitative polymerase chain reaction assay targeting the BamH I-W region of the EBV genome $[19,20]$. Serum lactate dehydrogenase, albumin and globulin measurements were performed with an automated immunoturbidmetric analyzer (7600-020; Hitachi High-Technologies, Tokyo, Japan). Blood counts were performed using a Sysmex XE-5000 automated hematology analyzer (Sysmex, Kobe, Japan).

\section{Treatment}

All patients were treated using IMRT with one fraction daily 5 days per week. The prescribed radiation dose was: a total dose of 68-70 Gy in 30-33 fractions at 2.13-2.27 Gy/fraction to the planning target volume (PTV) of the GTV-P, 60-70 Gy to the nodal gross tumor volume PTV (GTV-N), 60 Gy to the PTV of CTV-1 (high-risk regions), and 54-56 Gy to the PTV of CTV-2 (low-risk regions and neck nodal regions). During the study period, institutional guidelines recommended no chemotherapy for T2N0 disease and concurrent chemotherapy for T1-2N1 disease. Neoadjuvant chemotherapy was administered when the waiting time for radiotherapy was considered to be longer than acceptable $(>4$ weeks) or when it was considered advantageous to downsize bulky tumors. In total, 209/296 (70.6\%) patients received chemotherapy, of whom 191 (64.5\%) received concurrent chemotherapy. Concurrent 
chemotherapy consisted of cisplatin every 3 weeks or cisplatin weekly. Neoadjuvant chemotherapy consisted of two or three cycles of cisplatin with 5 -fluorouracil, or cisplatin with taxanes every 3 weeks.

\section{Follow-up}

After completion of therapy, patients were examined every 3 months during the first 2 years, and every 6 months thereafter for up to 5 years or until death. Median follow-up was 50.2 months (range, 8-69.5 months). No patients were lost to follow-up. The following end points (time to first defining event) were assessed: distant metastasis-free survival (DMFS), progression-free survival (PFS), local relapse-free survival (LRFS) and overall survival (OS).

\section{Statistical analysis}

All calculations were performed using Statistical Package for the Social Sciences, version 20.0 (SPSS, Chicago, IL, USA). Grouping of patients by serum LDH level and hemoglobin was carried out using standard or previously published thresholds [13, 21]. A cutoff of 4,000 copies/mL was chosen to define low and high EBV DNA levels; when using the same assay, this threshold has previously been shown to be prognostic for distant failure in patients with early-stage NPC [4]. Leukocyte counts and serum albumin and globulin levels were analyzed as binary variables using the median values as cut-off levels, which is more than or equal to median as the high group and less than median as the low group. Survival rates were analyzed using the Kaplan-Meier method and compared using the log-rank test in univariate analysis. Multivariate analysis using a Cox proportional hazards model was used to test independent significance by backward elimination of insignificant explanatory variables. Pearson chi-square $(x 2)$ tests or Fisher's exact test (when the expected number per cell was $<5$ ) was used to analyze categorical variables. A two-tailed $P$-value less than 0.05 was considered statistically significant.

\section{Results} outcomes

Clinicopathological features and treatment

The clinicopathological characteristics of the 296 patients, including 205 (69.3\%) males and 91 (30.7\%) females, are presented in Table 1 . The median age at diagnosis was 44 years (range, 20-77). Based on the World Health Organization criteria, $99.7 \%$ of patients had type II or III disease and $0.3 \%$ had type I disease. All patients were staged according to the 7 th edition of the AJCC staging system for NPC [16].

By last follow-up, 36/296 patients (12.2\%) had experienced tumor progression after treatment, including $25(8.4 \%)$ who developed local or regional recurrence and $17(5.7 \%)$ who developed distant metastasis. By the end of follow-up, 9/296 patients (3.0\%) had died of NPC. The 3-year OS, PFS, DMFS, and LRFS rates were $98.6 \%, 89.1 \%, 94.6 \%$, and $93.2 \%$, respectively.

Table 1. Univariate analysis of risk factors for distant metastasis and tumor progression.

\begin{tabular}{|c|c|c|c|c|c|}
\hline Factor & No. $(\%)$ & $\begin{array}{l}\text { 3-year } \\
\text { DMFS, \% }\end{array}$ & $P$-value & $\begin{array}{l}\text { 3-year } \\
\text { PFS, \% }\end{array}$ & $P$-value \\
\hline Age, years & & & 0.840 & & 0.690 \\
\hline$<50$ & $213(72.0)$ & 94.8 & & 90.1 & \\
\hline$\geq 50$ & $83(28.0)$ & 93.9 & & 86.6 & \\
\hline Sex & & & 0.229 & & 0.755 \\
\hline Male & $205(69.3)$ & 93.6 & & 89.2 & \\
\hline Female & $91(30.7)$ & 96.7 & & 89.0 & \\
\hline Family history of cancer & & & 0.964 & & 0.790 \\
\hline No & $193(65.2)$ & 94.8 & & 89.6 & \\
\hline Yes & $103(34.8)$ & 94.1 & & 88.3 & \\
\hline Clinical stage & & & 0.934 & & 0.655 \\
\hline T1N1 & $134(45.2)$ & 95.5 & & 91.0 & \\
\hline $\mathrm{T} 2 \mathrm{~N} 0$ & $49(16.6)$ & 93.9 & & 89.8 & \\
\hline $\mathrm{T} 2 \mathrm{~N} 1$ & $113(38.2)$ & 93.7 & & 86.6 & \\
\hline $\begin{array}{l}\text { Cervical lymph node } \\
\text { metastasis }\end{array}$ & & & 0.408 & & 0.129 \\
\hline Absent & 135 (45.6) & 95.5 & & 91.8 & \\
\hline Present & $161(54.4)$ & 93.7 & & 86.8 & \\
\hline $\begin{array}{l}\text { Location of positive } \\
\text { cervical lymph nodes }\end{array}$ & & & 0.149 & & 0.339 \\
\hline Suprahyoid region & $247(83.4)$ & 95.1 & & 90.3 & \\
\hline Hypohyoid region & $49(16.6)$ & 91.7 & & 83.3 & \\
\hline $\begin{array}{l}\text { MAD of cervical lymph } \\
\text { nodes, mm }\end{array}$ & & & 0.030 & & 0.014 \\
\hline$<30$ & $270(91.2)$ & 95.5 & & 90.3 & \\
\hline$\geq 30$ & $26(8.8)$ & 84.6 & & 76.9 & \\
\hline $\begin{array}{l}\text { Extracapsular spread of } \\
\text { cervical lymph nodes }\end{array}$ & & & 0.046 & & 0.110 \\
\hline Absent & $255(86.1)$ & 95.7 & & 90.1 & \\
\hline Present & $41(13.9)$ & 87.8 & & 82.9 & \\
\hline Chemotherapy & & & 0.100 & & 0.032 \\
\hline No & $87(29.4)$ & 97.7 & & 94.3 & \\
\hline Yes & $209(70.6)$ & 93.2 & & 88.0 & \\
\hline $\begin{array}{l}\text { Plasma EBV DNA level, } \\
\text { copies/mL }\end{array}$ & & & 0.012 & & 0.095 \\
\hline$<4000$ & $216(73.0)$ & 96.7 & & 90.7 & \\
\hline$\geq 4000$ & $80(27.0)$ & 88.7 & & 85.0 & \\
\hline Leukocytes, $\mathrm{k} / \mathrm{cc}$ & & & 0.391 & & 0.628 \\
\hline$<6.7$ & $149(50.3)$ & 96.0 & & 90.6 & \\
\hline$\geq 6.7$ & 147 (49.7) & 93.1 & & 87.7 & \\
\hline Hemoglobin, g/L & & & 0.320 & & 0.914 \\
\hline$<120$ & $16(5.4)$ & 100.0 & & 87.5 & \\
\hline$\geq 120$ & $280(94.6)$ & 94.2 & & 89.2 & \\
\hline $\begin{array}{l}\text { Serum lactate } \\
\text { dehydrogenase, } \mathrm{U} / \mathrm{L}\end{array}$ & & & 0.753 & & 0.671 \\
\hline$<245$ & $283(95.6)$ & 94.7 & & 89.3 & \\
\hline$\geq 245$ & $13(4.4)$ & 92.3 & & 84.6 & \\
\hline Serum albumin, $\mathrm{g} / \mathrm{L}$ & & & 0.455 & & 0.469 \\
\hline$<46.0$ & $148(50.0)$ & 93.9 & & 87.1 & \\
\hline$\geq 46.0$ & $148(50.0)$ & 95.3 & & 91.2 & \\
\hline Serum globulin, g/L & & & 0.025 & & 0.033 \\
\hline$<29.5$ & $146(49.3)$ & 91.8 & & 84.9 & \\
\hline$\geq 29.5$ & $150(50.7)$ & 97.3 & & 93.3 & \\
\hline
\end{tabular}




\section{Prognostic factors for distant metastasis and tumor progression}

Univariate analysis identified a cervical lymph node MAD $\geq 30 \mathrm{~mm}(P=0.030)$, extracapsular spread of cervical lymph nodes $(P=0.046)$, a plasma EBV DNA level $\geq 4,000$ copies $/ \mathrm{mL}(P=0.012)$ and serum globulin level $<29.5 \mathrm{~g} / \mathrm{L}(P=0.025)$ as significant prognostic factors for poor DMFS. The cervical lymph node $\operatorname{MAD}(P=0.014)$, chemotherapy $(P=0.032)$ and serum globulin level $(P=0.033)$ were also significantly associated with PFS (Table 1). The Kaplan-Meier curves for DMFS are shown in Figure 1.

Multivariate analysis for DMFS was performed to adjust for various prognostic factors (Table 2). Plasma EBV DNA level, cervical lymph node MAD and serum globulin were validated as independent prognostic factors for distant metastasis in patients with stage II NPC $(P=0.018 ; P=0.019 ; P=0.006$, respectively).

\section{Prognostic model for distant metastasis in stage II NPC}

We constructed a prognostic model for distant metastasis in stage II NPC. Patients were divided into
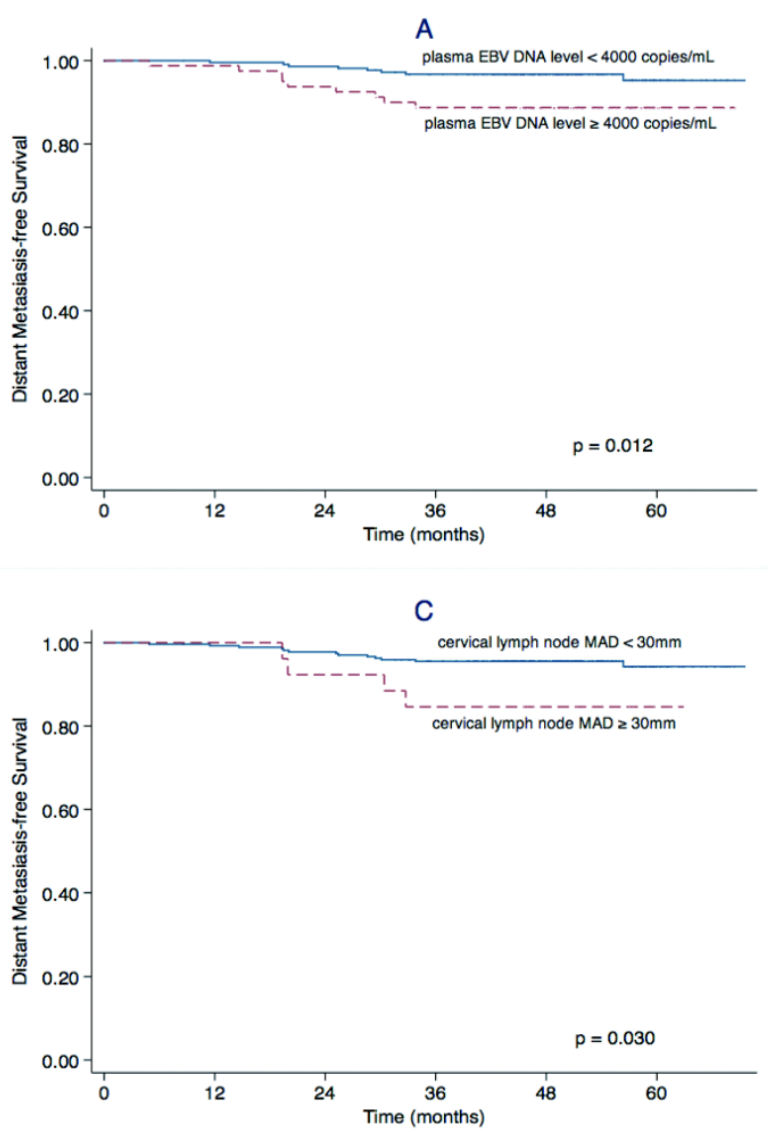

three subgroups according to the pre-treatment plasma EBV DNA, globulin level and cervical lymph node MAD as follows: 1 ) patients with 0 risk factors (97 patients); 2) patients with 1 risk factor (148 patients); and 3) patients with 2-3 risk factors (51 patients). The main clinical features of patients in each subgroup are presented in Table 3. The 3-year DMFS rates for groups 1, 2 and 3 were $100 \%, 94.6 \%$ and $84.3 \%(P=0.001)$ and the 3-year PFS rates were $95.8 \%$, $89.2 \%$ and $78.3 \%$, respectively $(P=0.002)$. The DMFS and PFS curves for the three groups clearly separated from each other (Figure 2).

Table 2. Multivariate analysis of risk factors for distant metastasis.

\begin{tabular}{|c|c|c|c|c|}
\hline Factor & Unfavorable & Favorable & HR $(95 \%$ CI) & $P$-value \\
\hline $\begin{array}{l}\text { Cervical lymph node } \\
\text { MAD }\end{array}$ & $\geq 30 \mathrm{~mm}$ & $<30 \mathrm{~mm}$ & $\begin{array}{l}4.213 \\
(1.263-14.053)\end{array}$ & 0.019 \\
\hline $\begin{array}{l}\text { Extracapsular spread of } \\
\text { cervical lymph nodes }\end{array}$ & Present & Absent & & \\
\hline Plasma EBV DNA level & $\begin{array}{l}\geq 4000 \\
\text { copies } / \mathrm{mL}\end{array}$ & $\begin{array}{l}<4000 \\
\text { copies } / \mathrm{mL}\end{array}$ & $\begin{array}{l}3.243 \\
(1.224-8.594)\end{array}$ & 0.018 \\
\hline Serum globulin & $<29.5 \mathrm{~g} / \mathrm{L}$ & $\geq 29.5 \mathrm{~g} / \mathrm{L}$ & $\begin{array}{l}5.375 \\
(1.612-17.928)\end{array}$ & 0.006 \\
\hline
\end{tabular}

Abbreviations: MAD, maximal axial diameter; $95 \%$ CI: 95\% confidence interval; HR: hazard ratio.
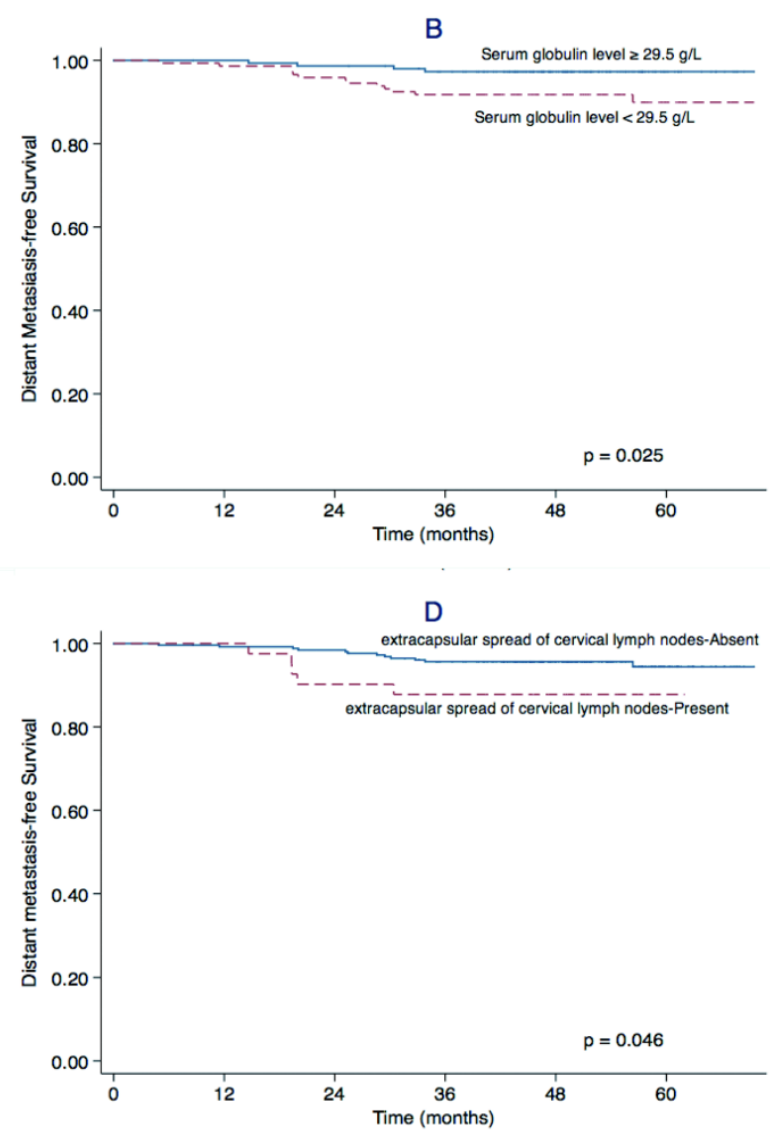

Figure 1. Factors related outcome regarding DMFS. Kaplan-Meier distant metastasis-free survival (DMFS) curves for patients with stage II NPC stratified by plasma EBV DNA level (A), serum globulin concentration (B), maximal axial diameter (MAD) of the cervical lymph nodes (C), and extracapsular spread of cervical lymph nodes (D). 

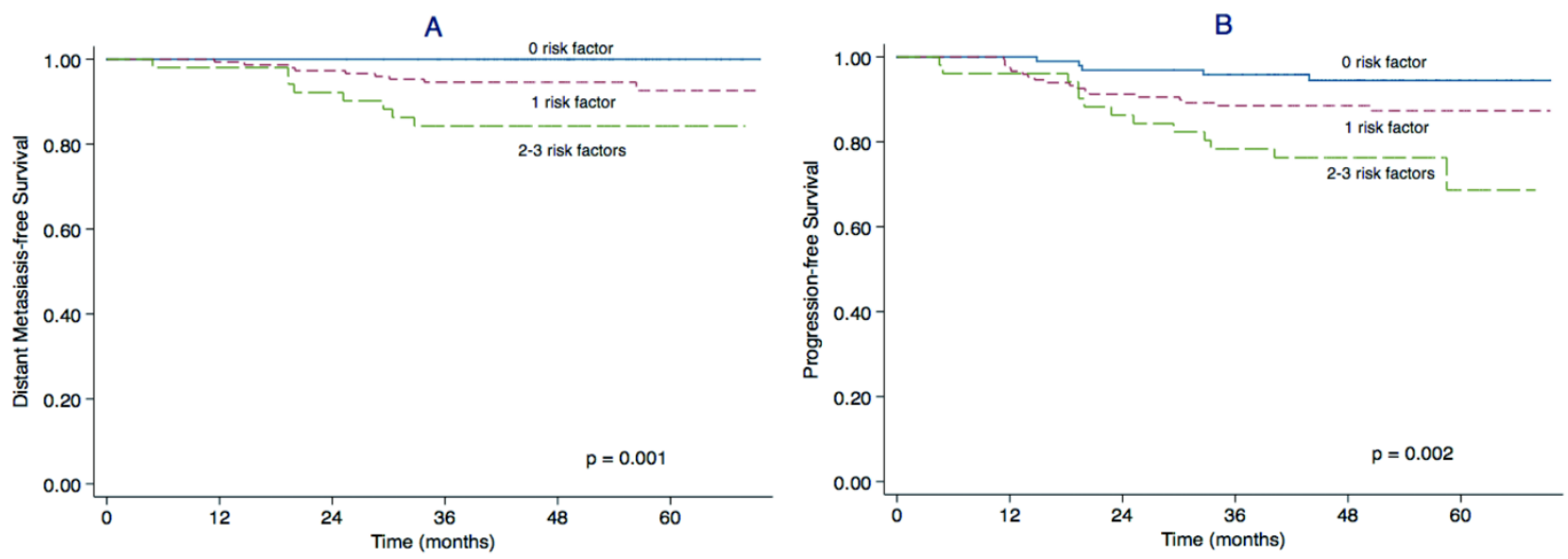

Figure 2. Prognostic model for DMFS and PFS in stage II NPC. Kaplan-Meier distant metastasis-free survival (DMFS) curves (A) and progression-free survival (PFS) curves (B) for patients with stage II NPC stratified using the prognostic score model based on plasma EBV DNA, serum globulin and maximal axial diameter (MAD) of the cervical lymph nodes.

Table 3. Characteristics of the three subgroups of patients stratified by plasma EBV DNA level, globulin concentration and nodal size.

\begin{tabular}{|c|c|c|c|c|}
\hline Factor & $\begin{array}{l}0 \text { risk } \\
\text { factor }\end{array}$ & 1 risk factor & $\begin{array}{l}2-3 \text { risk } \\
\text { factors }\end{array}$ & $P$-value \\
\hline & No. $(\%)$ & No. $(\%)$ & No. $(\%)$ & \\
\hline Age, years & & & & 0.225 \\
\hline$<50$ & $64(66.0)$ & 109 (73.6) & $40(78.4)$ & \\
\hline$\geq 50$ & $33(34.0)$ & $39(26.4)$ & $11(21.6)$ & \\
\hline Sex & & & & 0.143 \\
\hline Male & $63(64.9)$ & $101(68.2)$ & $41(80.4)$ & \\
\hline Female & $34(35.1)$ & $47(31.8)$ & $10(19.6)$ & \\
\hline Family history of cancer & & & & 0.188 \\
\hline No & $65(67.0)$ & $90(60.8)$ & $38(74.5)$ & \\
\hline Yes & $32(33.0)$ & $58(39.2)$ & $13(25.5)$ & \\
\hline Clinical stage & & & & 0.002 \\
\hline T1N1 & $42(43.3)$ & $70(47.3)$ & $22(43.1)$ & \\
\hline $\mathrm{T} 2 \mathrm{~N} 0$ & $25(25.8)$ & $23(15.5)$ & $1(2.0)$ & \\
\hline T2N1 & $30(30.9)$ & $55(37.2)$ & $28(54.9)$ & \\
\hline $\begin{array}{l}\text { Cervical lymph node } \\
\text { metastasis }\end{array}$ & & & & $<0.001$ \\
\hline Absent & $60(61.9)$ & $71(48.0)$ & $4(7.8)$ & \\
\hline Present & $37(38.1)$ & $77(52.0)$ & $47(92.2)$ & \\
\hline $\begin{array}{l}\text { Location of positive cervical } \\
\text { lymph nodes }\end{array}$ & & & & $<0.001$ \\
\hline Suprahyoid region & $88(90.7)$ & $127(85.8)$ & $32(62.7)$ & \\
\hline Hypohyoid region & $9(9.3)$ & $21(14.2)$ & $19(37.3)$ & \\
\hline $\begin{array}{l}\text { Extracapsular spread of } \\
\text { cervical lymph nodes }\end{array}$ & & & & $<0.001$ \\
\hline Absent & $91(93.8)$ & $129(87.2)$ & 35 (68.6) & \\
\hline Present & $6(6.2)$ & $19(12.8)$ & $16(31.4)$ & \\
\hline Chemotherapy & & & & $<0.001$ \\
\hline No & $42(43.3)$ & $38(25.7)$ & 7 (13.7) & \\
\hline Yes & $55(56.7)$ & $110(74.3)$ & $44(86.3)$ & \\
\hline
\end{tabular}

\section{Discussion}

To the best of our knowledge, this is the first report to create a prognostic model for distant metastasis based on pre-treatment clinical features and laboratory variables in stage II NPC. Nodal size is an important prognostic factor that reflects the tumor burden, thus to be included in the UICC/AJCC staging system. Compared to palpation-based greatest dimension of cervical lymph nodes, the MAD measured on MRI imaging was considered to be more accurate in evaluating nodal size [22]. Although previous studies failed to demonstrate the prognostic value of nodal MAD [22, 23], we suggested a cervical lymph node $M A D \geq 30 \mathrm{~mm}$ as potential stratification factor for AJCC 2009 stage II NPC patients.

Consistent with previous findings in both early-stage NPC $[4,24]$ and all stages of NPC $[12,24$, 25], a high pre-treatment plasma EBV DNA level was prognostic for distant metastasis after IMRT in AJCC 2009 stage II NPC. EBV, also called human herpes virus 4, has one of the highest human infection rates. EBV and its gene products are associated with the non-keratinizing subtypes of NPC in the endemic region, and the virus plays both a pathogenic and prognostic role in NPC. With the development of a quantitative real-time polymerase chain reaction assay for EBV DNA in recent years, numerous groups have confirmed that the circulating EBV DNA concentration is significantly associated with tumor stage, residual disease, distant metastasis, and OS [4, 12, 24-27]. The circulating EBV DNA concentration has been demonstrated to be a sensitive marker of tumor burden in NPC and a high pre-treatment plasma EBV DNA level has been linked to the manifestation of occult distant metastases $[4,24]$.

Furthermore, this is the first report that a high pre-treatment serum globulin level was associated with favorable DMFS in stage II NPC. High globulin levels are thought to arise due to elevated accumulation of acute-phase proteins, immunoglobulins and other serum proteins, which are reflective of both an inflammatory state and the host humoral immune response. As a virus-associated human cancer, NPC exhibits the characteristic 
histopathologic features of a dense inflammation-rich background [28]. In contrast to the normal antitumor functions, tumor-infiltrating immune cells are considered to facilitate the progression of NPC by producing chemokines and cytokines [29]. Additionally, as a non-specific response secondary to tumor necrosis or local tissue damage caused by tumor-host cell interactions, systemic inflammation may further promote tumor growth by inducing metabolic disturbances [30]. There is increasing evidence that systemic inflammation promotes an unfavorable outcome in various types of cancer. However, it is of interest to note that although a number of systemic inflammation-based factors are predictive of poor survival in NPC, a high serum globulin level seems to be a superior prognosticator for lower risk of distant metastasis in stage II NPC. This finding is in contrast to our previous study in advanced stage NPC [15].

To explain the disparity in the prognostic value of the serum globulin level in patients with different clinical stages of NPC, we hypothesize the host humoral immune response is mostly responsible for elevated serum globulin levels in early-stage NPC, while systemic inflammation may mainly regulate serum globulin levels in advanced disease. Several facts support this hypothesis. Firstly, EBV usually persists as a latent infection within the host before carcinogenesis occurs. Compared to healthy EBV carriers, patients with NPC have higher titers of serum immunoglobulins against EBV proteins, which are mainly associated with the virus replicative/lytic cycle [29]. These serological alterations are reflective of the host immune humoral response and indicative of adaptive immunity induced by aberrant reactivation of the virus from the latent phase into the replicative/lytic phase, and are often observed in advance to tumor development [31]. According to the cancer immunoediting theory, the host immune system interacts with the tumor in three sequential phases: elimination, equilibrium and escape. In the elimination phase, host innate and adaptive immunity co-operate as an extrinsic tumor suppressor. However, tumor cells may not be completely eliminated and enter into an equilibrium phase, during which adaptive immunity controls the growth of the tumor and at the same time edits tumor cell immunogenicity, selecting for cells with increased capacity to survive immune attack. Finally, the edited tumor cells with reduced immunogenicity begin to progressively grow in the escape phase $[32,33]$. Thus, despite the fact that tumor cells possess systemic immunodeficiency during the progression of NPC [32], the efficient humoral immune response against EBV proteins that occurs during early-stage disease may possibly reduce the risk of occult metastasis and lead to a better clinical outcome. Secondly, there is evidence that the systemic inflammatory response may play a greater role in advanced disease, as reflected by the higher serum acute-phase protein concentrations observed in patients with locally advanced NPC compared to early-stage disease [34].

Similarly to most other human tumor types, the major challenges in NPC treatment are assessment of the risk of metastasis and the development of preventive treatments. Our prognostic model combines the prognostic ability of the plasma EBV DNA, globulin levels and nodal size with the clinical implications of both tumor burden and the host immune responses. Based on this model, patients with stage II NPC could be separated into three risk groups with distinct survival outcomes. Additionally, the prognosis of patients with stage II disease who had more than one risk factors was similar to that of patients with locally advanced disease treated with IMRT [35]. This suggests the proposed prognostic model is a good complement to the TNM classification for NPC.

The major limitations of this study are its retrospective single-center design and the lack of measurement of the specific constituents of serum globulin. It would be of interest to further investigate the nature of the host humoral response towards EBV and its relationship with prognosis in NPC. Furthermore, a prospective study is required to validate the proposed prognostic model.

In conclusion, plasma EBV DNA, globulin levels and cervical lymph node MAD are independent prognostic factors for distant metastasis in stage II NPC and were combined to create a prognostic model that could be used to select patients who may benefit from combined therapy. The findings of this study may be useful when designing future clinical trials that focus on the management of early-stage NPC.

\section{Acknowledgments}

This work was supported by grants from the Health \& Medical Collaborative Innovation Project of Guangzhou City of China (201400000001) and the National Science \& Technology Pillar Program during the Twelfth Five-year Plan Period (2014BAI09B10).

\section{Conflict of interest}

The authors declare no conflict of interest.

\section{References}

1. Muir C, Waterhouse J, Mack T. Cancer incidence in five continents. IARC Sci Publ. 1987;5:1-970

2. Lee $\mathrm{AW}$, Lin JC, Ng WT. Current management of nasopharyngeal cancer. Semin Radiat Oncol. 2012;22(3):233-44.

3. Loong $\mathrm{HH}, \mathrm{Chan} \mathrm{AT}$. Controversies in the systemic treatment of nasopharyngeal carcinoma. Oral Oncol. 2014;50(9):785-90. 
4. Leung SF, Chan AT, Zee B, et al. Pretherapy quantitative measurement of circulating Epstein-Barr virus DNA is predictive of posttherapy distant failure in patients with early-stage nasopharyngeal carcinoma of undifferentiated type. Cancer. 2003;98(2):288-91.

5. Xiao WW, Han F, Lu TX, Chen CY, Huang Y, Zhao C. Treatment outcomes after radiotherapy alone for patients with early-stage nasopharyngeal carcinoma. Int J Radiat Oncol Biol Phys. 2009;74(4):1070-6.

6. Chua DT, Sham JS, Kwong DL, Au GK. Treatment outcome after radiotherapy alone for patients with stage I-II nasopharyngeal carcinoma. Cancer. 2003;98(1):74-80.

7. Su SF, Han F, Zhao C, et al. Long-term outcomes of early-stage nasopharyngeal carcinoma patients treated with intensity-modulated radiotherapy alone. Int J Radiat Oncol Biol Phys. 2012;82(1):327-33.

8. Luo S, Zhao L, Wang J, et al. Clinical outcomes for early-stage nasopharyngeal carcinoma with predominantly WHO II histology treated by intensity-modulated radiation therapy with or without chemotherapy in nonendemic region of China. Head Neck. 2014;36(6):841-7.

9. Chen QY, Wen YF, Guo L, et al. Concurrent chemoradiotherapy vs radiotherapy alone in stage II nasopharyngeal carcinoma: phase III randomized trial. J Natl Cancer Inst. 2011;103(23):1761-70.

10. Lee N, Xia P, Quivey JM, et al. Intensity-modulated radiotherapy in the treatment of nasopharyngeal carcinoma: an update of the UCSF experience. Int J Radiat Oncol Biol Phys. 2002; 53:12-22.

11. Kam MK, Teo PM, Chau RM, et al. Treatment of nasopharyngeal carcinoma with intensity-modulated radiotherapy: the Hong Kong experience. Int J Radiat Oncol Biol Phys. 2004; 60:1440-50.

12. Lin JC, Wang WY, Chen KY, et al. Quantification of plasma Epstein-Barr virus DNA in patients with advanced nasopharyngeal carcinoma. N Engl J Med. 2004;350(24):2461-70

13. Zhou GQ, Tang LL, Mao YP, et al. Baseline serum lactate dehydrogenase levels for patients treated with intensity-modulated radiotherapy for nasopharyngeal carcinoma: a predictor of poor prognosis and subsequent liver metastasis. Int J Radiat Oncol Biol Phys. 2012;82(3):e359-e365.

14. He JR, Shen GP, Ren ZF, et al. Pretreatment levels of peripheral neutrophils and lymphocytes as independent prognostic factors in patients with nasopharyngeal carcinoma. Head Neck. 2012;34:1769-76.

15. Du XJ, Tang LL, Mao YP, et al. The Pretreatment albumin to globulin ratio has predictive value for long-term mortality in nasopharyngeal carcinoma. Plos one. 2014; 9(4): e94437.

16. Edge SB, Byrd DR, Compton CC, et al. American Joint Committee on Cancer manual for staging of cancer, 7th ed. Philadelphia: JB Lippincott; 2009.

17. van den Brekel MW, Stel HV, Castelijns JA, et al. Cervical lymph node metastasis: assessment of radiologic criteria. Radiology. 1990;177:379-84.

18. Tang L, Li L, Mao Y, et al. Retropharyngeal lymph node metastasis in nasopharyngeal carcinoma detected by magnetic resonance imaging: prognostic value and staging categories. Cancer. 2008;113:347-54.

19. Lo YM, Chan LY, Lo KW, et al. Quantitative analysis of cell-free Epstein-Barr virus DNA in plasma of patients with nasopharyngeal carcinoma. Cancer Res. 1999;59:1188e1191.

20. Hou X, Zhao C, Guo Y, et al. Different clinical significance of pre- and post-treatment plasma Epstein-Barr virus DNA load in nasopharyngeal carcinoma treated with radiotherapy. Clin Oncol. 2001;23(2):128-33.

21. Jin $Y$, Cai XY, Cai YC, et al. To build a prognostic score model containing indispensible tumour markers for metastatic nasopharyngeal carcinoma in an epidemic area. Eur J Cancer. 2012;48(6):882-8.

22. Li WF, Sun Y, Mao YP, et al. Proposed lymph node staging system using the International Consensus Guidelines for lymph node levels is predictive for nasopharyngeal carcinoma patients from endemic areas treated with intensity modulated radiation therapy. Int J Rad Oncol Biol Phys. 2013;86:249-256.

23. Guo Q, Pan J, Zong J, et al. Suggestions for lymph node classification of UICC/AJCC staging system: a retrospective study based on 1197 nasopharyngeal carcinoma patients treated with intensity-modulated radiation therapy. Medicine (Baltimore). 2015;94(20):e808.

24. Leung SF, Zee B, Ma BB, et al. Plasma Epstein-Barr viral deoxyribonucleic acid quantitation complements tumor-node-metastasis staging prognostication in nasopharyngeal carcinoma. J Clin Oncol. 2006;24(34):5414-8.

25. Lin JC, Chen KY, Wang WY, et al. Detection of Epstein-Barr virus DNA in the peripheral-blood cells of patients with nasopharyngeal carcinoma: relationship to distant metastasis and survival. J Clin Oncol. 2001;19:2607-2615

26. Spratt DE, Lee N. Current and emerging treatment options for nasopharyngeal carcinoma. Onco Targets Ther. 2012;5:297-308.

27. Wang WY, Twu CW, Chen $\mathrm{HH}$, et al. Long-term survival analysis of nasopharyngeal carcinoma by plasma Epstein-Barr virus DNA levels. Cancer. 2013;119(5):963-70.

28. Chang KC, Chang Y, Wang LH, Tsai HW, Huang W, Su IJ. Pathogenesis of virus-associated human cancers: Epstein-Barr virus and hepatitis B virus as two examples. J Formos Med Assoc. 2014;113(9):581-90.

29. Gourzones C, Barjon C, Busson P. Host-tumor interactions in nasopharyngeal carcinomas. Semin Cancer Biol. 2012;22(2):127-36.

30. Balkwill F, Mantovani A. Inflammation and cancer: back to Virchow? Lancet. 2001;357(9255):539-45.

31. Coghill AE, Hildesheim A. Epstein-Barr virus antibodies and the risk of associated malignancies: review of the literature. Am J Epidemiol. 2014;180(7):687-95
32. Chow MT, Moller A, Smyth MJ. Inflammation and immune surveillance in cancer. Semin Cancer Biol. 2012;22(1):23-32.

33. Dunn GP, Bruce AT, Ikeda H, Old LJ, Schreiber RD. Cancer immunoediting: from immunosurveillance to tumor escape. Nat Immunol. 2002;3(11):991-8

34. Xia WX, Zhang HB, Shi JL, et al. A prognostic model predicts the risk of distant metastasis and death for patients with nasopharyngeal carcinoma based on pre-treatment serum C-reactive protein and N-classification. Eur J Cancer. 2013;49(9):2152-60.

35. Chen L, Mao YP, Xie FY, et al. The seventh edition of the UICC/AJCC staging system for nasopharyngeal carcinoma is prognostically useful for patients reated with intensity-modulated radiotherapy from an endemic area in China. Radiother Oncol. 2012;104(3):331-7. 